\title{
Cushing's disease: Results of treatment and factors affecting outcome
}

\author{
Ariachery C. Ammini, ${ }^{1}$ Saptarshi Bhattacharya, ${ }^{1}$ Jaya Praksh Sahoo, ${ }^{1}$ Jim Philip, ${ }^{1}$ \\ Nikhil Tandon, ${ }^{1}$ Ravinder Goswami, ${ }^{1}$ Viveka P. Jyotsna, ${ }^{1}$ Rajesh Khadgawat, ${ }^{1}$ \\ Sunil Chumber, ${ }^{2}$ Aashu Seth, ${ }^{3}$ Asis K. Karak ${ }^{4}$, Bhawani S. Sharma, ${ }^{5}$ \\ Poodipedi Sarat Chandra, ${ }^{5}$ Ashish Suri, ${ }^{5}$ Manish S. Sharma, ${ }^{5}$ Shashank S. Kale, \\ Manmohan Singh ${ }^{5}$
}

Departments of Endocrinology ${ }^{1}$, Surgery ${ }^{2}$, Radiology3, Pathology ${ }^{4}$ and Neurosurgery ${ }^{5}$, All India Institute of Medical Sciences, New Delhi, India

\begin{abstract}
OBJECTIVE: To analyze the therapeutic results of intervention and the factors affecting the outcome of patients with Cushing's disease (CD) cared for at the All Indian Institute of Medical Science (AIIMS), New Delhi. DESIGN. Patients with Cushing's disease treated at a teritiary care centre from January 2000 to December 2009 were prospectively studied. RESULTS. Ninetyseven patients received treatment for $\mathrm{CD}$ during this period. Mean duration of follow-up was $3.4 \pm 2.2($ mean \pm SD) years. Eighty-one patients $(83.5 \%)$ underwent transsphenoidal surgery (TSS) as the primary treatment modality. Fifty-four patients $(66.7 \%)$ went into remission after initial TSS; ten $(18.5 \%)$ of them relapsed after a mean follow-up period of $2.9 \pm 2.1$ (mean \pm SD) years. Histopathologic examination of resected tissue showed corticotroph adenoma in 48 of the $54(88.9 \%)$ who went into remission and 17 of the $27(63.0 \%)$ who did not go into remission after the initial TSS. Sixteen patients with severe hypercortisolism underwent bilateral adrenalectomy (BA) as a life-saving measure which was followed by pituitary surgery 6 to 12 months later. Five patients including one with a large macroadenoma required three or more procedures to achieve eucortisolism. CONCLUSION: Fifty-four out of 81 (66.7\%) of our patients with CD had remission following initial TSS, ten of whom relapsed later on. Sixteen patients unerwent BA as a life-saving procedure. Factors affecting outcome were, age, gender, low dose dexamethasone suppression test cortisol value and histologic confirmation of corticotroph adenoma.
\end{abstract}

Key words: ACTH dependent hyper cortisolism, Cushing's disease, Cushing's syndrome, Ectopic ACTH, Hypercortisolism, Transphenoidal pituitary surgery

Address for correspondence:

A.C. Ammini, Dept of Endocrinology, AIIMS, New Delhi, India, Tel.: +91 11 26593237, Fax: +91 11 26589162, e-mail: aca433@yahoo.com

Received 05-04-11, Revised 05-06-11, Accepted 20-06-11

\section{INTRODUCTION}

Cushing's syndrome (CS) is a complex endocrine disorder with potential for serious consequences if not promptly and adequately treated..$^{1-10}$ The clini- 
cal features are due to the effect of chronic cortisol excess on various tissues. The most common cause of endogenous $\mathrm{CS}$ is pituitary corticotroph adenoma (Cushing's disease - CD). There are few published reports from India which describe the outcome of treatment of CD. ${ }^{11-17}$ We present our experience of patients with $\mathrm{CD}$ who were treated during the last 10 years at the All Indian Institute of Medical Science (AIIMS), a tertiary referral centre caring for large parts of India, our objective being to analyze the therapeutic outcome and the factors affecting it.

\section{METHODOLOGY}

From January 2000 till December 2009, 121 patients were treated for ACTH-dependent CS in our centre (AIIMS). The duration of follow-up post therapeutic intervention ranged from 1.5 to 11 years. The mean age of the study group was $25 \pm 16.5$ (median \pm IQR) years (range 8 to 63 years); 31 (26\%) patients were $\leq 18$ years of age, $82(63 \%)$ were female.

The diagnostic approach and treatment intervention as well as the subsequent follow-up data of the $\mathrm{CD}$ patients who were evaluated and treated in the endocrine services of our hospital from January 2000 to December 2009 were analyzed. Information regarding demographics, preoperative assessment, procedures performed, histopathology reports and outcomes were recorded prospectively for each patient during initial evaluation and subsequent hospital visits. Following surgery, the patients were examined at 3 months, 6 months and yearly thereafter.

CS was suspected on the basis of history and physical examination and confirmed by biochemical and imaging studies. The tests which were used for diagnosis of CS were: 1) overnight dexamethasone suppression test (ONDST) using 1mg dexamethasone (cortisol value $<5 \mu \mathrm{g} / \mathrm{dl}$ being considered suppressed); 2) low dose dexamethasone suppression test (LDDST) using dexamethasone tablet $0.5 \mathrm{mg}$ given 6 hourly for 2 days (cortisol value $<1.8 \mu \mathrm{g} / \mathrm{dl}$ being considered suppressed). ${ }^{6,714,18}$ Those with discordant results and those with low serum cortisol in the absence of history of steroid use were subsequently re-evaluated to exclude the possibility of periodic hypercortisolism. Salivary cortisol value at 23:00 >0.43 $\mu \mathrm{g} / \mathrm{dL}$ was considered positive and was used during the last two and half years as an additional test. ${ }^{19}$

ACTH-dependent CS was diagnosed when plasma ACTH was more than $10 \mathrm{pg} / \mathrm{ml}(2.2 \mathrm{pmol} / \mathrm{L}){ }^{6,18}$ These patients underwent high dose dexamethasone suppression test (HDDST) (2mg dexamethasone tablet every $6 \mathrm{hr}$ for 48 hours (greater than $80 \%$ reduction in cortisol values being considered suppressed). All patients with ACTH-dependent hypercortisolism underwent MRI of the pituitary with dynamic sequences following gadolinium administration. ACTHdependent CS patients with normal or inconclusive (lesion less than $5 \mathrm{~mm}$ ) findings on MRI were further investigated for evidence of ectopic source of ACTH by a contrast-enhanced CT and or MRI scan of neck, chest, abdomen and pelvis. ${ }^{68} \mathrm{Ga}$ DOTA-NOC PET $\mathrm{CT}$ and ${ }^{18} \mathrm{FDG}$ PET-CT scan and bilateral internal jugular venous (IJV) ACTH sampling were done as additional tests as they became available. For IJV, a central/peripheral ACTH ratio of more than 1.6 was taken as suggestive of Cushing's disease.

Serum cortisol, salivary cortisol and plasma ACTH were determined by electrochemiluminescence immunoassay. ${ }^{19}$ The measuring range of cortisol assay was $0.018 \mu \mathrm{g} / \mathrm{dL}$ to $63.4 \mu \mathrm{g} / \mathrm{dL}$ with inter-assay and intra-assay $\mathrm{CV}<5.6 \%$. Plasma ACTH was determined using two monoclonal antibodies specific for ACTH (ACTH: 9-12 \& ACTH: 36-39). The measuring range of the ACTH assay was $1-2000 \mathrm{pg} / \mathrm{ml}$ with inter-assay and intra-assay $\mathrm{CV}<6 \%$. MRI was performed on a 1.5T scanner (Siemens Avanto or Sonata, Erlangen, Germany). T1W spin echo sequences were obtained in the coronal and sagittal planes using thin slices $(3 \mathrm{~mm})$. Additional T2 fast spin echo sequences were performed in the coronal plane. Patients received an intravenous gadolinium compound at a dose of $0.1 \mathrm{mmol} / \mathrm{kg}$. Post-contrast T1W images were obtained in the coronal plane. Following contrast administration, both dynamic and routine images were performed. For dynamic imaging fat suppressed fast spin echo sequences were used.

TSS was the preferred treatment if a pituitary adenoma could be localized by pre-operative investigations. The procedure consisted of either a trans nasal trans sphenoidal approach (TNTS) or a sublabial rhinoseptal transphenoidal approach (SRTS). A total excision was performed for both pituitary micro- and 
macroadenomas leaving the pituitary stalk intact. For microadenomas ( $<1 \mathrm{~cm}$ size), following the opening of the dura over the sella floor, the side showing localization was first explored under the operating microscope. If this was negative, the sella was then arbitrarily divided into 4 quadrants and each quadrant was sequentially explored for an adenoma. If this too proved negative, then a partial hypophysectomy was performed towards the side localized by pre-surgical investigations.

Bilateral total adrenalectomy (BA) was undertaken in $\mathrm{CD}$ patients with features of severe hypercortisolism as a life-saving procedure. In cases in which the source of ACTH excess could not be localized with available investigations, the patients were informed of the benefits and risks of pituitary exploration, BA and medical therapy. In such cases, therapy was provided as per patient's choice. Patients who underwent BA were re-evaluated for source of ACTH 6 months later and if negative yearly thereafter. Pituitary surgery or gamma knife (GK) therapy was carried out if a pituitary lesion was identified. Clinical evaluation and estimation of plasma cortisol and ACTH were done for all patients yearly.

Plasma cortisol was estimated 24 hours after surgery (before starting hydrocortisone) or 24 hours after stopping steroid, one week later. A serum cortisol value less than $2 \mu \mathrm{g} / \mathrm{dL}$ was considered as remission and a serum cortisol value between 2 and $5 \mu \mathrm{g} / \mathrm{dL}$ was considered as possible remission. ${ }^{8}$ Patients who were not considered to be in remission were re-evaluated again 3 months after surgery for possible remission. Patients in definite or possible remission were discharged on physiologic replacement doses of oral prednisolone and re-evaluated at 3 and 6 months to check if steroids could be withdrawn. Subsequently patients were followed yearly by physical examination and determination of plasma cortisol, ACTH and dexamethasone suppressed cortisol. In the case of a patient with $\mathrm{CD}$ in whom pituitary surgery failed or in whom there was recurrence of disease, decision regarding further treatment was taken on an individual basis and in consultation with the neurosurgeon. Those with residual or recurrent tumor had either a second surgery or GK therapy. If no lesion was detected, patients were subjected to BA and followed up.
Definitive diagnosis of CD was made when a pituitary adenoma was identified on imaging and/or histopathological examination, or when hypercortisolism remitted following pituitary surgery or on development of pituitary adenoma following BA. Cases in which the source of ACTH could not be identified were labeled as 'unknown' source of ACTH.

Statistical analysis was done using SPSS version 15. Data are presented as number $(\%)$ or mean \pm standard deviation (SD) or median \pm IQR as appropriate. The predictors of remission were analyzed using Fisher's exact test for categorical variables and student's $t$ test for quantitative variables. P value $<0.05$ was considered as statistically significant.

\section{RESULTS}

Pituitary corticotroph adenoma was the cause of hypercortisolism in 97 out of $121(80 \%)$ patients. In $14(11.7 \%)$ patients ACTH producing tumor was detected and in ten $(8.3 \%)$ the source of ACTH excess could not be identified (Figure 1). The source of ectopic ACTH was carcinoid in seven patients (four bronchial and three thymic), metastatic carcinoma in four (squamous cell carcinoma, adenocarcinoma and small cell carcinoma of lungs and one metastatic neuroendocrine tumor of unknown primary site), pancreatic tumor in two and multiple endocrine neoplasia type 2 (MEN2) with ectopic ACTH secretion from medullary carcinoma of the thyroid in one patient.

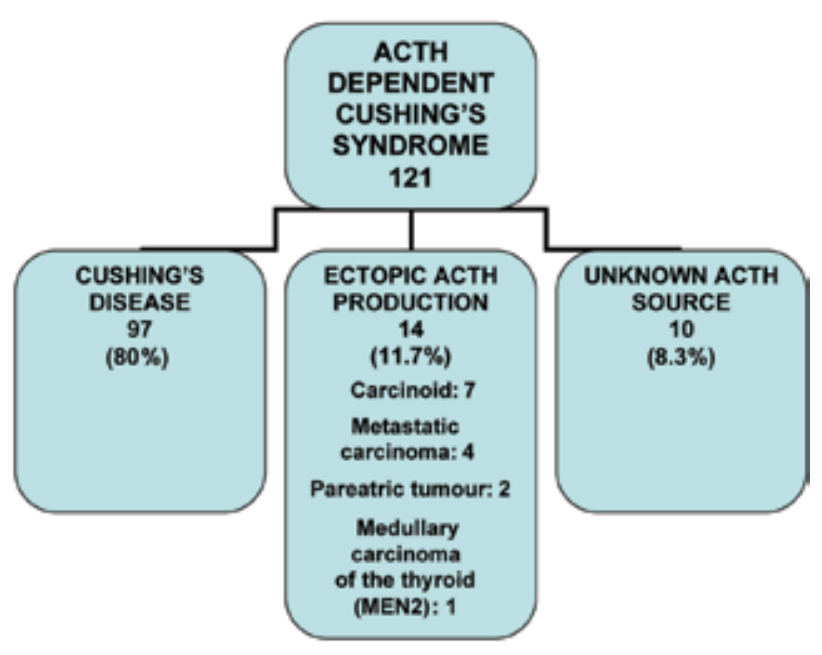

Figure 1. Source of ACTH excess. 
Eighty-one out of 97 patients with CD (83.5\%) underwent transphenoidal pituitary adenectomy (TSS) as the primary modality of treatment (Figure 2). Among them 13 had pituitary macroadenoma. Fifty-four (66.7\%) of these patients went into remission. Forty-four patients continue to be in remission (follow-up 18 months to 9 years, mean \pm SD $2.9 \pm 2.1$ years). Ten patients developed recurrence after a mean duration of $2.1 \pm 1.8$ years (range 1 to 7 years) (Figure 2). A second TSS was done in five (all are in remission) and three are awaiting repeat TSS. BA was done for one patient in whom no pituitary lesion was visible on MRI. She has completed a two-year follow-up and the recent MRI did not reveal any pituitary lesion. One patient died during follow-up.

Twenty-seven (33.3\%) patients did not go into remission after the initial TSS (Figure 3). Eight of these patients underwent second TSS or GK therapy (three went into remission, five required adrenalectomy / medical therapy), nine BA (seven had no pituitary lesion on follow-up ranging from 2 to 9 years, mean $5.1 \pm 1$ years) and nine are on medical therapy. One patient died during follow-up.

Histopathology examination of resected specimen showed corticotroph adenoma in 48 of the 54 who went into remission and 17 of the 27 who did not go into remission after the initial TSS.

Sixteen patients with CD with severe hypercortisolism underwent bilateral adrenalectomy as a life-saving measure. Two patients died during the peri-operative period (one of myocardial infarction and one of chest infection). The others had TSS (except one 13-year old girl with nonpneumatised sella who underwent GK therapy) done during the following 6 to 12 months). Ten were cured with the first TSS, 1 required a $2^{\text {nd }}$ TSS and two required TSS twice plus GK therapy. Four (4.1\%) patients died; two following adrenalectomy (one due to chest infection and another due to myocardial infarction) during the post-operative period, one had recurred after an initial successful TSS and the other had undergone an unsuccessful pituitary surgery. Cause of death was infection in the last two cases.

There was no difference in the rate of remission

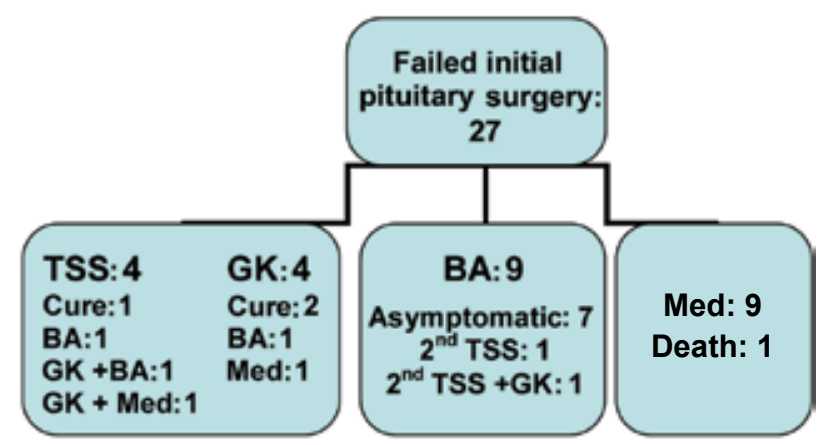

Figure 3. Follow-up of the 27 patients without remission following initial pituitary surgery.

BA: bilateral adrenalectomy; GK: gamma knife; med: medical theraly; TSS: transsphenoidal surgery.

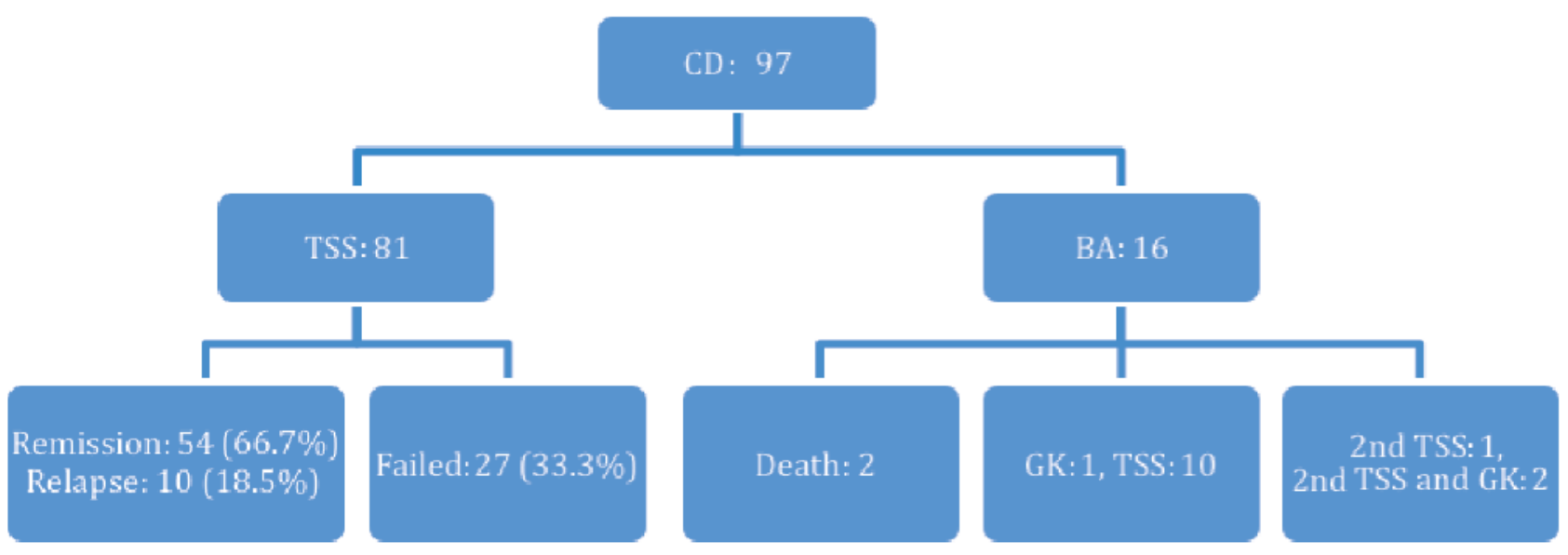

Figure 2. Type of therapeutic intervention in patients with Cushing's disease and outcome.

BA: bilateral adrenalectomy; CD: Cushing's disease; GK: gamma knife; TSS: transsphenoidal surgery. 
between patients with micro- or macroadenoma. There were five patients who required three or more procedures, one with a large macroadenoma, three with microadenoma and one with normal pituitary on MRI. The patient with macroadenoma underwent TSS twice followed by GK therapy and subsequently BA for control of hypercortisolism. The other four patients had initially failed TSS and later required multiple interventions.

Out of the 97 cases with CD, MRI showed a pituitary tumor in $75(77.3 \%), 16$ of which were macroadenomas. In none of the 14 ectopic cases did the MRI reveal any adenoma. Sixty percent of the cases with CD had positive HDDST.

In looking for the role of different factors in predicting remission after TSS as the initial treatment modality we performed univariate analysis (Table1). Lower age $(p=0.035)$ and lower LDDST serum cortisol value $(p=0.001)$ were the variables which could predict remission following TSS. Patients with lower baseline serum cortisol value at 08:00 also had an indicative trend towards achieving a higher chance of remission, though the association was not statistically significant $(\mathrm{p}=0.090)$. Female gender and presence of corticotroph adenoma in the resected tissue was also associated with higher remission rate (Table 1), the probability of remission for females being 2.7 higher compared to males.

\section{DISCUSSION}

CD accounts for $80-85 \%$ of cases of endogenous $\mathrm{CS}^{2-5}$ and in such cases TSS for excision of pituitary adenoma is the preferred treatment modality. ${ }^{21-35}$ The success rate for TSS in large series describing outcome of more than 100 patients has varied from $69 \%$ to $90 \% .^{21-35}$ Different parameters like size of the adenoma, dural invasion, localization on preoperative imaging, intraoperative tumor visualization, preoperative $\mathrm{ACTH}$, urinary cortisol and histological confirmation of corticotroph adenoma have been considered to predict remission following TSS..$^{27,30,38-47}$ An earlier study from India reported a remission rate of $77 \%$ for CD patients with microadenoma and $36 \%$ for those with macroadenoma following TSS. ${ }^{15}$

The present study included 121 patients with ACTH dependent CS, 97 (80\%) of which were due

Table 1. Factors affecting remission following transsphenoidal surgery

\begin{tabular}{|c|c|c|c|c|}
\hline & & $\begin{array}{c}\text { Remission } \\
\mathrm{n}=54\end{array}$ & $\begin{array}{c}\text { No Remission } \\
\mathbf{n}=27 \\
\end{array}$ & p value \\
\hline Age (yrs) & & $24.7 \pm 9.2$ & $29.7 \pm 9.9$ & 0.035 \\
\hline BMI $\left(\mathrm{Kg} / \mathrm{m}^{2}\right)$ & & $26.1 \pm 4.9$ & $27.5 \pm 6.8$ & 0.37 \\
\hline 08:00 serum cortisol $(\mathrm{nmol} / \mathrm{L})^{*}$ & & $780.9 \pm 251$ & $926.9 \pm 488.3$ & 0.09 \\
\hline 08:00 plasma ACTH (pmol/L)* & & $13.2 \pm 16.2$ & $11 \pm 13.3$ & 0.97 \\
\hline LDDST cortisol (nmol/L)* & & $529.7 \pm 251$ & $775.2 \pm 347.6$ & 0.001 \\
\hline \multirow[t]{2}{*}{ Gender n (\%) } & Male & $17(39.5)$ & $26(60.5)$ & 0.026 \\
\hline & Female & $37(63.8)$ & $21(36.2)$ & \\
\hline \multirow[t]{2}{*}{ Blood pressure n (\%) } & High & $43(65.2)$ & $23(34.8)$ & 0.118 \\
\hline & Normal & $11(68.8)$ & $5(31.2)$ & \\
\hline \multirow[t]{2}{*}{ Diabetes mellitus n (\%) } & Present & $20(57.1)$ & $15(42.9)$ & 0.212 \\
\hline & Absent & $34(73.9)$ & $12(26.1)$ & \\
\hline \multirow{2}{*}{$\begin{array}{l}\text { High dose dexamethasone suppression test } \\
\mathrm{n}(\%)\end{array}$} & Positive & $28(67.7)$ & $14(33.3)$ & 0.118 \\
\hline & Negative & $19(70.4)$ & $8(29.6)$ & \\
\hline \multirow[t]{2}{*}{ Adenoma size $\mathrm{n}(\%)$} & Microadenoma & $46(67.6)$ & $22(32.4)$ & 0.06 \\
\hline & Macroadenoma & $8(57.5)$ & $6(42.9)$ & \\
\hline \multirow[t]{2}{*}{ Biopsy n (\%) } & Positive for corticotroph adenoma & $48(73.8)$ & $17(26.2)$ & 0.021 \\
\hline & Negative for corticotroph adenoma & $6(37.5)$ & $10(62.5)$ & \\
\hline
\end{tabular}

*Values in mean \pm SD 
to $\mathrm{CD}$ and $14(12 \%)$ to ectopic $\mathrm{ACTH}$ production. The source of ACTH could not be identified in ten patients (8\%). Eighty-one CD cases had TSS as the primary modality of treatment and of them 54 (67\%) had remission. Twenty-seven who did not go into remission with initial TSS required further interventions which included TSS, GK therapy or BA.

BA was performed in 16 patients with severe hypercortisolism as a life-saving procedure. Pituitary adenectomy (GK therapy for one girl with nonpneumatised sella) was carried out in these patients 6 to 12 months later.

The source of ACTH excess remains unknown in ten cases; one of them had a pituitary microadenoma at the time of initial evaluation which has remained unchanged in size for 7 years after bilateral adrenalectomy.

Mortality was higher compared to previous similar studies $^{24,35,50}$ during immediate postoperative period among patients who underwent bilateral adrenalectomy most likely because of severe hypercortisolism. Two more patients died during follow-up because of infection. One of them had persistent hypercortisolism after TSS and the other had relapsed after initial remission following TSS. Hammer et al reported three deaths during the initial 30 days following surgery in a large cohort of nearly 300 patients. ${ }^{35}$ During subsequent follow up they observed higher mortality among subjects with persistent disease ${ }^{35}$ whereas Atkinson et $\mathrm{al},{ }^{24}$ observed four deaths among 45 patients during follow, these patients being in remission.

Four of the five patients who required multiple procedures in the present study were patients with small microadenomas. We did not observe a difference in remission rate following TSS between CD patients with micro- or macroadenoma. This is unlike some previous reports which reported higher remission rates in patients with microadenoma compared to those with macroadenoma (65 to $90 \%$ vs less than $65 \%){ }^{15,35,50}$ Chee et al observed higher remission among those who had adenoma at surgery and on histopathology compared to those in whom both were negative. ${ }^{41}$ However, they observed no difference in remission rates in those with an adenoma on MRI vs those with normal pituitary on MRI. ${ }^{49}$
One probable reason behind failure to achieve remission following TSS in some of our patients could be adrenal autonomy in the setting of longstanding CS. This speculation is corroborated by the observation that seven patients with initial failure of pituitary surgery have not developed recurrence of corticotroph adenoma after BA. The CT imaging of adrenal glands of these seven patients had shown bilateral adrenal hyperplasia in six. There are reports indicating that longstanding $\mathrm{CD}$ has caused macronodular transformation of adrenals leading to persistent hypercortisolemia after pituitary surgery. ${ }^{48}$

In the present study, histological finding of corticotroph adenoma, a lower value of serum cortisol after LDDST and lower age at diagnosis were associated with higher chance of remission. Also, absence of diabetes mellitus and a lower baseline 08:00 serum cortisol value showed a trend towards correlation with achieving remission, though this association did not reach statistical significance. Higher LDDST cortisol value and the presence of diabetes may be markers of a more longstanding and severe disease. A negative finding for corticotroph adenoma on histopathology after TSS was most strongly associated with recurrence, the probability of remission being 7.75 lower compared to patients with a positive finding for corticotroph adenoma.

The strength of our study is that a large number of patients from a single centre was followed up by the same investigators for a relatively long period. The success rate of $67 \%$ with first TSS in our series is comparable to that reported in the literature. ${ }^{23-38}$ The main weakness of this study is that in about $8 \%$ of the patients the source of ACTH escaped detection. This is possibly due to non-availability of some essential investigations like CRH stimulated IPSS for ACTH determination.

\section{REFERENCES}

1. Lindholm J, Juul S, Jorgensen JO, et al, 2001 Incidence and late prognosis of Cushing's syndrome: a populationbased study. JCEM 86: 117-123.

2. Orth DN, 1995 Cushing's syndrome. N Engl J Med 332: 791-803.

3. Boscaro M, Barzon L, Fallo F, Sonino N, 2001 Cushing's syndrome. Lancet 357: 783-791. 
4. Bertagna X, Raux-Demay MC, Giulhaume B, Girard F, Luton JP 2002 Cushing's disease. In: Melmed S (ed) The pituitary, Malden, MA: Blackwell pp, 592-612.

5. Newell-Price J, Trainer P, Besser GM, Grossman AB, 1998 The diagnosis and differential diagnosis of Cushing's syndrome and pseudo-Cushing's states. Endocr Rev 19: 647-672.

6. Arnaldi G, Angeli A, Atkinson AB, et al, 2003 Diagnosis and complications of Cushing's syndrome: a consensus statement. J Clin Endocrinol Metab 288: 5593-5602.

7. Makras P, Toloumis G, Papadogias D, Kaltsas GA, Besser M, 2006 The diagnosis and differential diagnosis of endogenous Cushing's syndrome. Hormones (Athens) 5: 231-250.

8. Biller BM, Grossman AB, Stewart PM, et al, 2008 Treatment of adrenocorticotropin-dependent Cushing's syndrome: a consensus statement. J Clin Endocrinol Metab. 93: 2454-2462.

9. Newell-price J, Bertagna X, Grossman AB, Nieman LK, 2006 Cushing's syndrome. Lancet 367: 1605-1617.

10. American Society of Anesthesiologists, ASA Physical Status Classification System, Accessed at http://www. asahq.org/clinical/physicalstatus.htm on August 25, 2010.

11. Kriplani A, Buckshee K, Ammini AC, 1993 Cushing syndrome complicating pregnancy. Aust N Z J Obstet Gynaecol 33: 428-430.

12. Tripathi S, Ammini AC, Bhatia R, et al, 1994 Cushing's disease: pituitary imaging. Australas Radiol 38: 183-186.

13. Goswami R, Shah P, Ammini AC, Berry M, 1995 Healing of osteoporotic vertebral compression fractures following cure of Cushing's syndrome. Australas Radiol 39: 195197.

14. Biswas K, Goyal R, Ammini AC, et al, 2005 Recurrent lymphocytic hypophysitis in a woman 27 years after subtotal adrenelectomy for hypercortisolism possibly of autoimmune origin. JAPI 53: 1066-1069.

15. Shah NS, Goel AH, Nagpal RD, Menon PS, 2006 Cushing's disease: management outcome in a tertiary care centre. J Assoc Physicians India 54: 919-922.

16. Bhansali A, Walia R, Rana SS, et al, 2009 Ectopic Cushing's syndrome: experience from a tertiary care centre. Indian J Med Res 129: 33-41.

17. Mishra AK, Agarwal A, Gupta S, Agarwal G, Verma AK, Mishra SK, 2007 Outcome of adrenalectomy for Cushing's syndrome: experience from a tertiary care center. World J Surg 31:1425-1432.

18. Nieman LK, Biller BM, Dindling JW, et al, 2008 The diagnosis of Cushing's syndrome: an Endocrine Society Clinical Practice Guideline. J Clin Endocrinol Metab 93: 1526-1540.

19. Jeyaraman K, Ammini AC, Nandita G, Dwivedi SN, 2010 Late-night salivary cortisol in normal subjects and in patients with Cushing's syndrome. Postgrad Med J 86: 399-404.

20. Talbot JA, Kane JW, White A, 2003 Analytical and clini- cal aspects of ACTH determination. Ann Clin Biochem 40: 453-471.

21. Boggan JE, Tyrrell B, Wilson CB, 1983 Transsphenoidal microsurgical management of Cushing's disease. J Neurosurg 59: 195-200.

22. Fahlbusch R, Buchfelder M, Muller OA, 1986 Transsphenoidal surgery for Cushing's disease. JR Soc Med 79: 262-269.

23. Nakane T, Kuwayama A, Watanabe M, et al, 1987 Longterm results of transsphenoidal adenectomy in patients with Cushing's disease. Neurosurgery 21: 218-222.

24. Mampalam TJ, Tyrrell B, Wilson CB, 1988 Transsphenoidal microsurgery for Cushing's disease. Ann Intern Med 109: 487-493.

25. Ludecke DK, 1991 Transnasal microsurgery of Cushing's disease 1990. Overview including personal experiences with 256 patients. Pathol Res Pract 187: 608-612.

26. Ram Z, Nieman LK, Cutler GBJ, et al, 1994 Early repeat surgery for persistent Cushing's disease. J Neurosurg 80: 37-45.

27. Bochicchio D, Losa M, Buchfelder M, 1995 Factors influencing the immediate and late outcome of Cushing's disease treated by transsphenoidal surgery: a retrospective study by the European Cushing's Disease Survey Group. J Clin Endocrinol Metab 80: 3114-3120.

28. Knappe UJ, Ludecke DK, 1996 Persistent and recurrent hypercortisolism after transsphenoidal surgery for Cushing's disease. Acta Neurochir Suppl (Wien) 65: 31-34.

29. Sonino N, Zielezny M, Fava GA, et al, 1996 Risk factors and long-term outcome in pituitary dependent Cushing's disease. J Clin Endocrinol Metab 81: 2647-2652.

30. Invitti C, Giraldi FP, De Martin M, et al, 1999 Diagnosis and management of Cushing's syndrome: results of an Italian multi-centre study. J Clin Endocrinol Metab 84: 440-448.

31. Semple PL, Laws ER Jr, 1999 Complications in a contemporary series of patients who underwent transsphenoidal surgery for Cushing's disease. J Neurosurg 91:175-179.

32. Swearingen B, Biller BM, Barker FG 2nd, et al, 1999 Long-term mortality after transsphenoidal surgery for Cushing's disease. Ann Intern Med 130: 821-824.

33. Estrada J, Garcia-Uria JL, Lamas C, et al, 2001 The complete normalization of the adrenocortical function as the criterion of cure after transsphenoidal surgery for Cushing's disease. J Clin Endocrinol Metab 86: 5695-5699.

34. Chen JC, Amar AP, Choi S, Singer P, et al, 2003 Transsphenoidal microsurgical treatment of Cushing's disease: postoperative assessment of surgical efficacy by application of an overnight low-dose dexamethasone suppression test. J Neurosurg 98: 967-973.

35. Hammer GD, Tyrrell JB, Lamborn KR, et al, 2004 Transsphenoidal microsurgery for Cushing's disease: initial outcome and long term results. J Clin Endocrinol 
Metab 89: 6348-6357.

36. Porterfield JR, Thompson GB, Young WF Jr, et al, 2008 Surgery for Cushing's syndrome: an historical review and recent ten-year experience. World J Surg 32: 659677.

37. Walz MK, Alesina PF, Wenger FA, et al, 2006 Posterior retroperitoneoscopic adrenalectomy: results of 560 procedures in 520 patients. Surgery 140: 943-948.

38. Woo YS, Isidori AM, Wat WZ, et al, 2005 Clinical and biochemical characteristics of adrenocorticotropinsecreting macroadenomas. J Clin Endocrinol Metab 90: 4963-4969.

39. Rees DA, Hanna FW, Davies JS, Mills RJ, Vafidis J, Scanlon MF, 2002 Long-term follow-up results of transsphenoidal surgery for Cushing's disease in a single centre using strict criteria for remission. Clin Endocrinol (Oxf) 56: 541-551.

40. Blevins LS Jr, Christy JH, Khajavi M, Tindall GT, 1998 Outcomes of therapy for Cushing's disease due to adrenocorticotropin-secreting pituitary macro-adenomas. J Clin Endocrinol Metab 83: 63-67.

41. Chee GH, Mathias DB, James RA, et al, 2001 Transsphenoidal pituitary surgery in Cushing's disease: can we predict outcome? Clin Endocrinol (Oxf) 54: 617-626.

42. Bochicchio D, Losa M, Buchfelder M, 1995 Factors influencing the immediate and late outcome of Cushing's disease treated by transsphenoidal surgery: a retrospective study by the European Cushing's Disease Survey Group. J Clin Endocrinol Metab 80: 3114-3120.

43. Booth GL, Redelmeier DA, Grosman H, et al, 1998 Improved diagnostic accuracy of inferior petrosal sinus sampling over imaging for localizing pituitary pathology in patients with Cushing's disease. J Clin Endocrinol Metab 83: 2291-2295.

44. Burke CW, Adams CBT, Esiri MM, et al, 1990 Transsphenoidal surgery for Cushing's disease: does what is removed determine the endocrine outcome? Clin Endocrinol (Oxf) 33: 525-537.

45. Sonino N, Zielezny M, Fava GA, et al, 1996 Risk factors and long-term outcome in pituitary dependent Cushing's disease. J Clin Endocrinol Metab 81: 2647-2652.

46. Guilhaume B, Bertagna X, Thomsen M, et al, 1988 Transsphenoidal pituitary surgery for the treatment of Cushing's disease: results in 64 patients and long term follow-up studies. J Clin Endocrinol Metab 66: 10561064.

47. Arnott RD, Pestell RG, McKelvie PA, et al, 1990 A critical evaluation of transsphenoidal pituitary surgery in the treatment of Cushing's disease: prediction of outcome. Acta Endocrinol (Copenh) 123: 423-430.

48. Timmers HJ, van Ginneken EM, Wesseling P, Sweep CG, Hermus AR, 2006 A patient with recurrent hypercortisolism after removal of an ACTH-secreting pituitary adenoma due to an adrenal macro nodule. J Endocrinol Invest 29: 934-939.

49. Patil CG, Prevedello DM, Lad SP, et al, 2008 Late Recurrences of Cushing's Disease after Initial Successful Transsphenoidal Surgery. J Clin Endocrinol Metab 93: 358-362.

50. Atkinson AB, Kennedy A, Wiggam MI, McCance DR, Sheridan B, 2005 Long-term remission rates after pituitary surgery for Cushing's disease: the need for long-term surveillance. Clin Endocrinol (Oxf) 63: 549559. 